DR. EDOARDO PAPPAIANNI (Orcid ID : 0000-0001-8961-1956)

Article type : Special Issue Article

Reviewers: Alessandra Retico, National Institute for Nuclear Physics, Italy

Ciara Molloy, University of Rochester Medical Center, USA

Eugenia Conti, University of Pisa, Italy

Corresponding author email id: edoardo.pappaianni@unitn.it

\title{
Three shades of grey: detecting brain abnormalities in children with autism by using Source-, Voxel- and Surface-based Morphometry
}

\author{
Edoardo Pappaianni ${ }^{1}$, Roma Siugzdaite ${ }^{2}$, Sofie Vettori ${ }^{3}$, Paola Venuti ${ }^{1}$, Remo Job ${ }^{1}$, Alessandro \\ Grecucci $i^{1}$ \\ 1) Department of Psychology and Cognitive Sciences, University of Trento, Italy \\ 2) Department of Experimental Psychology, Faculty of Psychology and Pedagogical Sciences, \\ Ghent University, Belgium \\ 3) Center for Developmental Psychiatry, Department of Neurosciences, KU Leuven, Belgium
}

\begin{abstract}
Autistic spectrum disorder (ASD) is a neurodevelopmental disorder characterized by deficits in social interactions, communication and stereotyped behavior. Recent evidence from neuroimaging supports the hypothesis that ASD deficits in adults may be related to abnormalities in a specific frontal-temporal network (Autism-specific Structural Network, ASN). To see whether these results extend to younger children and to better characterize these abnormalities, we applied three morphometric methods on brain grey matter of children with and without ASD.
\end{abstract}

We selected 39 sMRI images of male children with ASD and 42 typically developing (TD) from the ABIDE database. We used Source-Based Morphometry (SoBM), a whole-brain multivariate approach to identify grey matter networks, Voxel-Based Morphometry (VBM), a voxel-wise comparison of the local grey matter concentration, and Surface-Based Morphometry (SuBM) for the estimation of the cortical parameters.

SoBM showed a bilateral frontal-parietal-temporal network different between groups, including the inferior-middle temporal gyrus, the inferior parietal lobule and the postcentral gyrus; VBM returned differences only in the right temporal lobe; SuBM returned a thinning in the right inferior temporal lobe thinner in ASD, a higher gyrification in the right superior parietal lobule in TD and in the middle frontal gyrus in ASD.

This article has been accepted for publication and undergone full peer review but has not been through the copyediting, typesetting, pagination and proofreading process, which may lead to differences between this version and the Version of Record. Please cite this article as doi: 10.1111/ejn.13704

This article is protected by copyright. All rights reserved. 
For the first time, we investigated the brain abnormalities in children with ASD by using three morphometric techniques. The results were relatively consistent between methods, stressing the role of an Autism-specific Structural Network in ASD individuals. We also make methodological speculations on the relevance of using multivariate and whole brain neuroimaging analysis to capture ASD complexity.

Keywords: Autism, MRI, VBM, Source based morphometry, Surface based morphometry.

\section{Introduction}

Autistic Spectrum Disorder (ASD) is defined as a behavioral disorder caused by neurodevelopmental problems reflecting dramatic cognitive, affective and behavioral deficits (Greenspan, 1997; Trevarthen et al., 1998; Venuti, 2003; Venuti, 2012). Based on World Health Organization, 1 child on 160 has a ASD disorder, and the diagnosis is globally increasing, probably due to more sensitive criteria (e.g. from DSM IV to DSM 5), or the application of more accurate tools of investigation (see www.who.int for information). ASD is characterized by severe and pervasive impairment in social and communication skills and by repetitive conduct patterns. The term spectrum (DSM 5) is meant to capture an umbrella of disorders that previously were diagnosed separately, namely autistic disorder, Asperger's disorder, childhood disintegrative disorder, Rett syndrome, and pervasive developmental disorder not otherwise specified (DSM-IV-TR). This is because ASD is characterized by a wide phenomenological and neural heterogeneity, that prevents a clear and specific investigation of the aforementioned disorder. Such complexity and heterogeneity posed problems to scientists interested in finding basic mechanisms behind such wide manifestations, but also to clinician to develop specific markers to make a clear diagnosis. Although researchers believe that ASD is characterized by a neurobiological origin, such heterogeneity has always been a challenge for autism research and for its clinical diagnosis. To overcome this shortcoming, researchers have focused their attention on specific brain alterations. However, results have been fragmented and quite confusing (Cauda et al., 2011; Grecucci et al., 2015). Several regions seem to be affected by ASD. A meta-analysis by Cauda and colleagues (2011) summarized several on grey matter abnormalities. Some studies reported increased grey matter in the cerebellum, the middle temporal gyrus, the right anterior cingulate cortex, the caudate, the insula, the fusiform gyrus, the precuneus and the posterior cingulate cortex seem all involved in ASD. Other studies showed reduced grey matter concentration in the cerebellar tonsil, inferior parietal lobule, middle temporal gyrus, right amygdala, insula, middle temporal gyrus, and others (Cauda et al., 2011). Another meta-analysis reported brain structures anomalies in ASD. Specifically, the authors found six consistent clusters relative to ASD pathology, that included the lateral occipital lobe, the pericentral region, the medial temporal lobe, the basal ganglia, the right parietal operculum (Nickl-Jockschat et al., 2012).

To make order in these apparently confusing results, researchers suggested the possibility to consider ASD deficits as belonging to a more large "social brain". Drawing from results from several studies, this network may consist of the amygdala (for emotion processing), the superior temporal sulcus and the fusiform gyrus (perception and recognition of faces), orbitofrontal cortex and superior frontal gyrus (facial imitation and theory of mind) (Brothers, 1990; Misra, 2014; Gordon \& Calamia, 2016). However, the "social brain" hypothesis does not clearly descend from actual brain data, but rather from theoretical

This article is protected by copyright. All rights reserved. 
assumptions (e.g. areas selected from separate studies based on their hypothetical involvement in autistic deficits). One problem with previous studies, is that researchers used different approaches, different ages, and mainly univariate approaches, or hypothesis driven approaches, thus missing the possibility of finding a whole brain ASD neural abnormalities.

Given the complexity and heterogeneity of ASD manifestations, only recently researchers advocated the necessity of novel approach to study ASD from a network perspective.

Recently, Grecucci and collaborators (2016) introduced an innovative approach to autism neural research called Source-Based Morphometry, a multivariate method able to detect maximally independent networks of grey matter from MRI data. They found a broad structural frontal-temporal network differing between adults with ASD and controls, that they called "Autism-specific Structural Network" (ASN), a set of regions selectively involved in social cognition, high-visual processing, and executive functions (Grecucci et al., 2016). They also found that the entity of grey matter abnormalities correlated with social and behavioral deficits as manifested by ASD. Another study tried to extend these results on younger children between 6 and 12 years old (Pappaianni et al., 2016). They found a significant network including several cerebellar regions (as Inferior Semi-lunar lobule, Tuble, Uvula, Pyramis, Declive and Cerebellar Tonsil) and the Fusiform Gyrus. However, these results refer to a wide age range ( 7 years in a critical development period), and the differences found may be due to different developmental trajectories between ASD and controls (Wegiel et al., 2014), rather than specific abnormalities due to ASD deficits.

The first aim of the present study is to extend Grecucci et al. (2016) results to younger individuals with ASD. To this aim we applied Source-Based Morphometry (SoBM) on children with and without ASD. To avoid possible confounds due to different developmental trajectories (as possibly displayed by Pappaianni et al., 2016), we restricted the age range of autistics and controls to a smaller range. We predict to find evidence of the ASN also in younger individuals with ASD, confirming and strengthening previous results (Grecucci et al., 2016). We want to put forward the idea that multivariate approaches (e.g. SoBM) might be preferred to univariate approaches (e.g. VBM) to study autism. Univariate approaches are largely used for neuropsychiatric research. However, such approaches may not be able to capture the heterogeneity and large brain scale deficits as presented by ASD individuals. To provide evidence of the usefulness of multivariate rather than univariate approaches to ASD, we performed on the same data both SoBM and VBM. Coherently with previous observations on other complex pathologies (e.g. schizophrenia, Xu et al., 2009), we predict SoBM to be more sensitive to detect brain abnormalities as compared to VBM.

To better understand the eventual neural abnormalities in ASD when compared to normal controls as detected by SoBM, we aim to perform Surface-Based Morphometry (SuBM), a novel approach to cortical analyses, that returns information about gyrification, thickness and sulci depth in the grey matter. SoBM is of great help to determine whole brain abnormalities in terms of large scale networks that covary inside each group, but that differently express between groups. However, it does not specify the nature of this difference. In other words, SoBM clarifies "where" is the problematic network. SuBM may

This article is protected by copyright. All rights reserved. 
help clarifying "what" is the problem in terms of gyrification, thickness and sulci depth abnormalities, inside that network.

Notably, by applying SuBM only, the goal of detecting the full features of the network behind ASD deficits may be missed, since the analysis of surface returns only the clusters of voxels that reach a given threshold without taking into account the relation between them; instead, SoBM does take into account such relevant relation. By applying both SoBM and SuBM we believe we will be able to have a more complete picture of ASD neural abnormalities.

\section{Participants and Methods}

We selected 39 male children with ASD (mean age 10.10 (0.98) years, age range 8-11) and 42 male TD control participants matched for age $(t(79)=1.99, p=0.21$ ) (mean age 10.39 (1.08) years, age range 8-11) from the Autism Brain Imaging Data Exchange (ABIDE) database (Di Martino et al., 2013). We took into account only participants that had full data on cognitive tasks of interest. Demographic information about participants is shown in Table 1 and detailed information about the selection is described below.

Structural MRI images of every participant were acquired from ABIDE. The acquisition parameters, informed consent, diagnostic criteria and specific protocols used in every site are available on the database website (http://fcon_1000.projects.nitrc.org/indi/abide/).

ABIDE initially returned 296 participants at age 8-12 available, but after a rigorous qualitative skimming, we excluded the ones with acquisition artifacts or incomplete behavioral data. We also included the intelligence scores (Full IQ, Verbal IQ and Performance IQ) derived from the Wechsler Abbreviated Scale of Intelligence (WASI), the Differential Ability Scales (DAS), and the Wechsler Intelligence Scale for Children (WISC) and the Autism Diagnostic Observation Schedule (ADOS) scores for the ASD population.

This accurate selection (matching based on age, sex and absence of corrupted data) has led to 81 male participants: 39 with ASD and 42 typically developing controls. These data were collected from different research centers (see Table 1 and 2). Particularly, among the participants with ASD, 28 participants were selected from NYU Langone Medical Center and 11 from University of California Los Angeles (specifically, 7 from UCLA Sample 1 and 4 from UCLA Sample 2). Regarding the typically developing controls, 18 were chosen from NYU, 14 from University of California Los Angeles (9 from UCLA-1 and 5 from UCLA-2), 8 from Yale Child Study Center and 2 from University of Pittsburgh, School of Medicine. The scanners used in these research centers were assembled by the same manufacturer. MRI scanners and acquisition protocols are described in Table 2. All remaining technical details are available on the database website (http://fcon_1000.projects.nitrc.org/indi/abide/).

\section{Preprocessing of the MRI images \\ Source-Based Morphometry}

Source-Based Morphometry is a multivariate method based on independent component analysis (ICA) (Lee, 1999; Xu et al., 2009) and it is defined as a whole-brain approach. ICA is a widely used technique for biomedical signal computations, and it has shown to be particularly suitable with fMRI, EEG and SMRI data (Calhoun \& Adali, 2006; Makeig et al., 
1997; Nakai et al., 2004; Xu et al., 2009). In the latter case, ICA detects and splits up the mixed signal coming from SMRI images, identifying independent sources (single regions or a network of areas) that covarying between participants, providing information about in grey matter among groups of individuals ( $\mathrm{Xu}$ et al., 2009). SoBM is defined as a data-driven approach: operating automatically on the whole brain, it tracks independently the $\begin{array}{llll}\text { unpredicted components } & \text { signal. } & \text { SPM12 } & \text { software }\end{array}$ (http://www.fil.ion.ucl.ac.uk/spm/software) was used for segmentation of grey matter, white matter and cerebrospinal fluid after a scrupulous quality check of the initial images for avoiding artifacts. Modulated normalized writing option was chosen. Stressing that we were interested only in grey matter for our research goals, we took advantage of Diffeomorphic Anatomical Registration using Exponential Lie algebra (DARTEL) tools, a potential alternative to SPM's traditional registration approaches that operates in a whole brain approach (Yassa \& Stark, 2009). Normalization to MNI space with spatial smoothing (full-width at half maximum of Gaussian smoothing kernel $[8,8,8]$ ) was then applied on DARTEL images. Source-Based Morphometry was performed by Group ICA of an FMRI Toolbox (GIFT, http://mialab.mrn.org/software/gift/). The software estimated autonomously the number of Independent Components (in our case, 9 sources). A neural network algorithm (Infomax) that exploits the signal-information coming from the images to maximize the recognition of independent components was used to perform ICA (Bell \& Sejnowski, 1995, Lee et al., 1999). ICASSO, a GIFT toolbox for investigating the reliability of the ICA algorithm (http://research.ics.aalto.fi/ica/icasso/) was selected as stability analysis type. Both Randlnit and Bootstrap modes were selected in ICASSO analysis. Independent Component Analysis was run 100 times: the minimum cluster size set up was 2, the maximum 9 (the number of components identified by the software). At the end, SoBM converts grey matter volumes of each component into a numerical vector, creating a matrix composed by rows (the participants) and columns (the sources). It follows that each numerical value of the matrix indicates how a specific component is expressed in each participant.

\section{Voxel-Based Morphometry}

Voxel-Based Morphometry is a cerebral morphometric technique that involves "a voxel-wise comparison of the local concentration of gray matter between two groups of subjects" (Ashburner \& Friston, 2000). VBM is a univariate method and follows a linear procedure of application (Xu et al., 2009). Voxel-Based and Source-Based Morphometry shared the same preprocessing phase. After the application of the spatial smoothing (full-width at half maximum of Gaussian smoothing kernel $[8,8,8]$ ), a set of voxel-wise parametric statistical tests allowed to determine how grey matter differed between groups and to establish how significant this difference is.

\section{Surface Based Morphometry}

The Computational Anatomy Toolbox (CAT12, http://www.neuro.uni-jena.de/cat/), a toolbox available for SPM12 software in the MATLAB environment, was used for preprocessing the images and for the surface analyses. All images together underwent automated segmentation to gray matter (GM), white matter (WM) and cerebrospinal fluid (CSF), affine registration to a MNI template space, and subsequently a non-linear deformation. This part resembles VBM preprocessing explained before. Using projectionbased thickness (PBT), that uses a projection scheme which considers 92 blurred sulci to create a correct cortical thickness map (Dahnke et al. 2012), we estimated cortical thickness

This article is protected by copyright. All rights reserved. 
and created the central cortical surface for left and right hemisphere. Cortical thickness is measured estimating the white matter distance between the inner surface (WM/GM boundary) and the outer surface (GM/CSF) of gray matter. Next, visual quality control was performed inspecting gray matter images. Newly created images were smoothed with $15 \mathrm{~mm}$ FWHM of Gaussian smoothing kernel and total intracranial volume (TIV) was calculated. We extracted several additional measures for surface, such as gyrification indices (GI) that measure surface complexity (Yotter et al. 2011b) and sulci depth. Gl is measured as a ratio of the external brain surface with the outer surface excluding the sulci. Gl calculation was based on absolute mean curvature (Luders et al. 2006). Square root transformed sulcus depth based on the euclidean distance between the central surface and its convex hull. Transformation with square root function was used to render the data more normally distributed (CAT12, manual).

\section{Statistical analyses}

In SoBM, a simple t-test without assuming equal variances on the matrix's loading coefficients was used to determine significant differences for every component between children with ASD and typical development ones. In addition, the same values were tested in a linear relation between the coefficients and the cognitive and ADOS available scores. In VBM, a whole-brain analysis was carried out, while group comparison was performed using a two samples t-test. Additionally, Age, Total Intracranial Volume (TIV) and Verbal IQ were used as covariate to increase the possibility of finding significant results. In SuBM, twosample t-tests (without and with age and VIQ as covariates) were used to find differences in gyrification, cortical thickness and sulci depth. All tests were corrected for multiple comparisons ( $p<0.05$, family wise error (FWE) correction at cluster-level), unless explicitly indicated.

\section{Results}

\section{Demographic results}

Groups did not differ for Age $(t(79)=-1.25, p=0.21)$, Full IQ $(t(79)=-0.71, p=0.48)$, Performance IQ $(t(79)=1.16, p=0.25)$ and Total Intracranial Volume $(t(79)=0.16, p=0.87)$. Only Verbal IQ resulted significantly different between groups $(t(79)=-2.38, p=0.02)$. We believe that this difference may be related to language and communicative deficits that characterize ASD in early childhood.

\section{Source-Based Morphometry results}

Independent Component Analysis returned 9 Independent Components. A matrix composed by 81 rows (the participants) and 9 columns (the sources) was obtained. We stress that the number of components was automatically recommended by GIFT toolbox based on the well-known Akaike's information criterion and not selected based on a priori knowledge. Among these, a network indicated as Independent Component number 7 (IC7) resulted to be significant after two-sample t-test between ASD and TD loading coefficients $(p=0.002)$. Specifically, this large network included the bilateral inferior-middle temporal gyrus, the postcentral gyrus, the precentral gyrus, the temporal sub-gyral gyrus, the supramarginal gyrus, the fusiform gyrus, the left insula, the superior temporal gyrus and the right uncus, the parahippocampal gyrus, the extra-nuclear and middle frontal gyrus. IC7 details are shown in Table 3, a visual rendering in Figure 1.

This article is protected by copyright. All rights reserved. 
As already said, ICA returned 9 components. Apart from IC7, the other 8 components resulted not to be significant after two-sample t-test. Specifically, we get IC1 $(p=0.46)$, IC2 $(p=0.13)$, IC3 ( $p=0.53)$, IC4 ( $p=0.50)$, IC5 $(p=0.76)$, IC6 ( $p=0.17)$, IC8 $(p=0.35)$, IC9 $(p=$ $0.44)$. A detailed description of the components is available in the Supplementary Materials.

\section{Voxel-Based Morphometry results}

Voxel-Based Morphometry returned only a cluster of voxels $(k=3310)$ in the right superior temporal gyrus significant between groups ( $p=0.006$, ASD vs TD contrast). No significant results were found in the left hemisphere and in the opposite contrast (i.e. TD vs ASD). To possibly improve results provided by VBM we then included Age, TIV and VIQ as covariates in the analysis. Age increased the significance $(p=0.003)$ in the same region, although the number of voxels slightly decreased $(k=2865)$; in addition, a trend of significance was observed in the left postcentral gyrus ( $k=569, p=0.06$, uncorrected). Using TIV, two wide clusters in the right superior temporal gyrus and left postcentral gyrus emerged $(k=6702, p$ $=0.001 ; \mathrm{k}=2608, \mathrm{p}=0.003)$, in addition to the left middle temporal gyrus $(\mathrm{k}=1274, \mathrm{p}=$ 0.005 unc.), the middle frontal gyrus (on the left hemisphere, $k=1026, p=0.01$ unc.; on the right, $k=1144, p=0.008$ unc.) and the right superior frontal gyrus ( $k=676, p=0.03$ unc.).

Verbal IQ confirmed the right superior temporal gyrus ( $k=5506, p=0.001)$, together with the right middle frontal gyrus ( $k=2604, p=0.005)$, the left inferior frontal gyrus $(k=2711, p$ $=0.004)$ and the left postcentral gyrus $(k=2782, p=0.003)$. In addition to this, the left superior temporal gyrus was found significant $(k=2048, p=0.02)$, whereas the right precuneus was found not significant after FWE correction ( $k=835, p=0.03$ unc.). Results from VBM with and without covariates (contrasts, Talairach labels of regions of interest, spatial coordinates and p-values on cluster-level, FWE corrected) are shown in Figure 2 and Table 4.

Summarizing, SoBM returned a bilateral network, incorporating wide temporal, frontal and parietal regions. Voxel-Based Morphometry returned only a region in the right temporal region; this result was confirmed and partially strengthened using age, TIV and in particular Verbal IQ as covariate (see Figure 2), although the clusters of significance especially in the left hemisphere resulted scattered and not able to fully describe the wide cerebral extension of the autistic condition (as expressed instead by SoBM).

\section{Surface-Based Morphometry results}

2-Sample t-tests on $15 \mathrm{~mm}$-smoothed surface images were performed. Specifically, we considered cortical thickness, sulci depth and gyrification as cortical parameters extracted during segmentation of GM, WM and CSF. Analyses were performed for each hemisphere separately. As a form of consistency, also in this case age and verbal IQ were considered as covariates in the analysis.

\section{Cortical thickness}

No significant results were found in left hemisphere; conversely, in the right hemisphere, a large cluster of voxels $(k=1024)$ resulted different between groups (Fig. 3, $p=0.004$ ). Children with ASD showed a lower cortical thinning in the temporal lobe, near the middle temporal gyrus. This result was confirmed by using age as covariate $(k=666, p=0.02)$ and powered with verbal IQ $(k=1352, p=0.001)$. See Table 5 for all details.

This article is protected by copyright. All rights reserved. 


\section{Cortical gyrification}

In the left hemisphere, no significant results were found in cortical local gyrification without covariates ( $p=0.09$ unc.) and with age ( $p=0.11$ unc.). Adding Verbal $I Q$, a trend of significance was observed in two clusters of the middle temporal gyrus in ASD vs TD contrast ( $k=227, p=0.05 ; k=201, p=0.07$, both uncorrected). In the right hemisphere, although not corrected for multiple comparisons, cortical gyrification appeared lower in ASD than TD in the superior parietal lobule (Fig. 3, $k=250, p=0.04$ unc.). This seemed confirmed by age ( $k=256, p=0.04$ unc.) and Verbal IQ ( $k=245, p=0.05$ unc.). Conversely, a trend of significance for increased gyrification in middle frontal gyrus in ASD children was observed ( $k=210, p=0.072$ unc.); while with age as covariate there were not significant results $(p=$ 0.09 ), with Verbal IQ a cluster in middle frontal gyrus resulted statistically increased in gyrification in children with ASD (Fig. 3, k=412, p=0.01). All details are shown in Table 5.

\section{Sulci depth}

In the left hemisphere, there was no significant difference in sulci depth between children with ASD compared to TD peers ( $p=0.16$ uncorrected in frontal areas). This was also the case using the usual covariates (for age, $p=0.29$; for $V I Q, p=0.18$ and $p=0.29$ all uncorrected). Also in the right hemisphere, there was no significant difference between children with ASD and controls ( $p=0.13$ uncorrected in middle frontal sulci). Using age as covariate, the same cluster did not reach the significance $(p=0.13$ unc.); adding Verbal IQ, two clusters near to cuneus and precuneus emerged, however not significantly between ASD and TD ( $p=0.07$ and $p=0.17$, unc.). See all details in Table 5 .

\section{Effect size}

In order to validate our results, the T-maps values obtained from the t-test contrasts were converted into effect size $d$, with uncorrected threshold type peak-level (0.001). Among voxels survive height threshold $u=3.2$, particularly results for cortical thickness (TD > ASD in middle temporal gyrus) and gyrification (ASD > TD in superior parietal lobule) were confirmed.

\section{Discussion}

In the present study, we applied Source-Based (SoBM), Voxel-Based (VBM) and SurfaceBased Morphometry (SuBM) on MRI images of children diagnosed with autism spectrum disorder and typical developing controls. SoBM is an innovative approach to study the neural abnormalities in autism. As a multivariate data-driven method, it exploits Independent Component Analysis (ICA) in order to extract clusters of grey matter covarying between participants as structural networks not defined a priori (Pappaianni et al., 2016; Grecucci et al., 2016; Xu et al., 2009). On the other hand, VBM is a univariate method that allows to find out relevant differences in grey matter concentration with a direct comparison in terms of clusters of voxels in the brain between groups. We want to put forward the idea that SoBM may be more appropriate for studying ASD because of its complexity and heterogeneity. ASD is clearly characterized by diffuse brain abnormalities that cover different regions at the same time, and these changes may be not locally detected with a univariate approach of parametric analysis (Grecucci et al., 2016). Taking advantage of the Independent Component Analysis, Source-Based Morphometry provided 9 independent sources extracted from the group of participants. Among these, a wide circuit that included mainly temporal, but also parietal and frontal regions (IC7) resulted 
significantly different between children with ASD and TD controls. This network specifically included the bilateral postcentral gyrus, the inferior temporal gyrus, the precentral gyrus, the temporal sub-gyral, the inferior parietal lobule, the supramarginal gyrus, the middle temporal gyrus, the fusiform gyrus; the left insula and the superior temporal gyrus; the right parahippocampal gyrus and the middle frontal gyrus.

In parallel, a cluster in the right superior temporal gyrus resulted different in ASD than controls when applying VBM. This result overlaps with SoBM findings. However, 1) this region is largely smaller, no frontal neither parietal extensions were visible, and no significant results emerged in the left hemisphere, showing that a univariate method as VBM fails to detect some important differences in a network logic. To investigate if covariates may help VBM to detect other regions more similar to SoBM, age, TIV and Verbal IQ were considered in the analysis. With the addition of these covariates, VBM showed other significant regions, such as the right middle frontal gyrus and the left superior temporal gyrus, areas included in IC7 (SoBM). Although VBM and SoBM overlap, we want to suggest that being SoBM a multivariate and whole brain approach, may be preferred when studying such complex neurobehavioral disorders (See Xu et al., 2009 for similar considerations).

In addition to these two approaches, to better investigate the nature of the network, we also applied SuBM to detect surface abnormalities that may help the interpretation of this ASD children specific circuit emerged with SoBM. In particular, cortical thickness, sulci depth and local gyrification were analyzed to find abnormal cortical alterations. For the sake of consistency, we introduced also in SuBM the same covariates already used in VBM, except for the TIV. Again, results in the right temporal lobe emerged in terms of cortical thickness: ASD showed a lower thickness of grey matter in temporal sub-gyral, specifically in middlesuperior temporal gyrus using VIQ as a covariate. Notably, although spatially very close, there is no direct overlap between the results of VBM and SuBM. This would lead to problems of interpretation, since on one hand grey matter volume resulted larger in the ASD's medial superior temporal regions and on the other a lower cortical thickness in ASD emerged. Instead, these less thick clusters seem to be included in the network described by SoBM. Since SoBM does not work on voxel level but on clusters covarying between subjects, we assume that this decrease in cortical thickness in these areas may be an important cortical parameter of covariance between participants with ASD within the IC7 network.

Significant results regarding the sulci depth did not emerged: we believe that a larger sample could have led to significance, since a possible trend for to deeper sulci in ASD than TD in medial frontal regions was observed, areas historically related to ASD (and included in our network IC7). This was already spotted in literature: indeed, abnormal patterns of sulci in ASD in central, intraparietal and frontal medial sulci were already found (Auzias et al., 2014). Nordahl and colleagues (2007) found in a young population with low-functioning autism a prominent abnormal shape in the inferior frontal gyrus associated with a sulcal depth difference in the anterior insula and frontal operculum, confirmed in high-functioning individuals although lesser extent but spatially more posterior (Nordahl et al., 2007).

This article is protected by copyright. All rights reserved. 
Abnormal gyrification has been observed repeatedly in ASD research, but results often have not been exhaustive and convergent, probably due to important differences in sample size, analysis methods, to the wide diversity in cortical gyrification observed also in healthy population or to the substantial change of cortical gyrification during the development (Bartley et al., 1997; Ecker et al., 2016; Armstrong et al., 1995). However, Yang and colleagues (2016) showed an age-related increment of gyrification in children with ASD referring to the right prefrontal lobe, the right temporal lobe, the left parietal lobe, together with a higher cortical gyrification in the temporal, the parietal, the occipital and cingulate cortex independently from age (Yang et al., 2016). The same year, Ecker and collaborators (2016) attempted to find a relation between local grey matter gyrification and white matter connectivity in ASD. In particular, they first found higher gyrification in left pre/post-central gyrus and white matter fiber tracts associated with these areas with a significant increment in axial diffusivity (Ecker et al.. 2016). There are also evidences about a gyrification increment in ASD's bilateral posterior cortices (Wallace et al., 2013), left frontal gyrification index higher in childhood and adolescence but not in adults (Hardan et al., 2004), but also reduced gyrification in left supramarginal gyrus in ASD than TD (Libero et al., 2014). From our analysis (with VIQ covariate), a strong increment of gyrification in the right middle frontal gyrus emerged in ASD, while TD controls seemed to have more expressed gyrification in the superior parietal lobule, a region near to the intraparietal sulcus. Although the results in the literature are various, we are inclined to believe that the frontal lobe in children with ASD may be affected by an abnormal structural pattern of gyrification, since it emerged as a recurrent area in our three parametric analyses likewise to the temporal lobe and partially to the parietal one. Regarding this, a smaller gyrification to the superiorposterior part of the parietal lobe may be linked to the motor difficulties typical of ASD children, although other studies will need to confirm this hypothesis to look for a more effective link.

Drawing from our three analyses, a key role for the temporal lobe in the characterization of ASD clearly emerges. This result is in line with previous observations. Zilbovicius and colleagues $(2000,2005)$ reported abnormalities in temporal regions of ASD individuals, areas implicated in social perception, language, and theory of mind (Gendry Meresse et al., 2005). Also the fusiform gyrus is commonly reported as linked to ASD, probably related to face processing difficulties (Rossion et al., 2003; Osterling \& Dawson, 1994) or to inability in focalizing attention to conspecific voice (Kuhl et al., 2005; Gordon \& Calamia, 2016). In addition, Kleinhans and colleagues (2008) found a weaker connectivity between fusiform face area (FFA) and other "social regions" (as the superior temporal sulcus, posterior cingulate and amygdala), in relation to high social deficit scores in ADI-R, an interview tool used in diagnosis of ASD (Kleinhans et al., 2008; Gordon \& Calamia, 2016). Also the superior temporal sulcus, implied in the perception of social acts, seem related to ASD (Zilbovicius et al., 2006). Then, it has been shown that people with ASD have problems in recognizing biological motion (Gordon \& Calamia, 2016). While healthy individuals can easily recognize actions of others (and even emotions) through kinematic patterns from lights attached to specific parts of the body (defined point-light walkers) (Johansson, 1973), for individuals with ASD this type of recognition is problematic (Black et al., 2003), and researchers found that this impairment may be related to a weaker activation of the superior temporal sulcus during the recognition task (Carter \& Pelphrey, 2006; Gordon \& Calamia, 2016). Other important clusters in our network emerged in frontal areas, regions involved in executive 
processes and language (Gotts et al., 2012; Libero et al., 2014). This part of the circuit included also precentral motor areas. Action processing impairments and repetitive movements are commonly observed among participants affected by autism (Grecucci et al., 2013). Frontal and precentral regions may be connected with mirror neuron dysfunctions in ASD. A theory known as the "broken mirror" hypothesis of ASD, suggested that a dysfunctional MNS is an important factor in AD pathogenesis (Oberman et al., 2005).

Looking more broadly, a meta-analysis by Cauda and colleagues (2011) summarized several results about autism research on brain morphometric measures. They demonstrate that grey matter of individuals with ASD is generally enlarged in the cerebellum, the middle temporal gyrus, the insula, the fusiform gyrus, the precuneus, the caudate and the cingulate cortex. A more recent meta-analysis of neuroimaging studies showed a specific lateralization in ASD compared to controls in communication and language tasks, with more right hemisphere activity in superior temporal gyrus and inferior frontal gyrus and a hypoactivation in MTG of both hemispheres (Herringshaw et al., 2016). In line with these outcomes, our VBM (and partially SoBM) results were affected by a right lateralization, in particular with the addition of Verbal IQ (a parameter strictly related to linguistic and communicative skills) in the VBM analysis. A recent investigation by Eilam-Stock and colleagues (2016) compared grey-matter volume in a quite large sample of high-functioning adults with autism and controls by using voxel-based morphometry. They found an increased volume of grey-matter in the frontal, temporal, and cerebellar brain regions in the ASD group. In particular, the right medial prefrontal cortex, the left superior frontal gyrus, the left inferior frontal gyrus (Broca's area), the middle temporal gyrus, and the cerebellum (VIIb) were found to be larger in ASD. Vice versa, the left posterior hippocampus and the bilateral cuneus were found less extended in the clinical population than in typically developing controls. Reflecting the fact that autism requires a large-scale study in terms of network than single regions, and that it is a unique and specific disorder about this feature, in a very recent research Conti and colleagues (2017) applied MRI diffusion tractography to images of ASD children compared with other neurodevelopmental disorder. They found an over-connectivity pattern specific and typical for ASD in networks concerning temporalfrontal nodes, in regions strictly related to social and communicative skills (Conti et al., 2017).

Summarizing, results emerged from the our three analyses (in particular with SoBM and VBM) seemed to be plausible and quite consistent with literature.

\section{The Autism-specific Structural Network (ASN)}

Our SoBM results is coherent with a previous study conducted by Grecucci and colleagues (2016), in which they used SoBM on adults with ASD and TD controls. They found an AutismSpecific Network (ASN), a specific circuit that involved the inferior-middle-superior frontal gyrus, the inferior-middle-superior temporal gyrus, the fusiform gyrus, the parahippocampal gyrus, the paracentral lobule, the precuneus and the cerebellar tonsil. Comparing Grecucci et al., (2016) ASN and our findings, a strong coherence and overlap emerges, especially in regard to the temporal and frontal regions. Notably, several parietal and temporal-parietal regions resulted in IC7, making the circuit wider but also sparser: the large size of this network (which incorporates even spatially distant regions) may be the confirmation of a widespread neural deficit in children. Our hypothesis is that with increasing age, the

This article is protected by copyright. All rights reserved. 
situation may tend to stabilize and different regions (or circuits) could be inclined to specialize and to be directly responsible for the various deficits characterizing the condition, justifying the correlations they found between ASN and ADOS scores that we did not. Including frontal and temporal areas, the ASN in adults may be linked mostly to the cognitive control, whereas the additional involvement of the parietal lobe in children may be associated more with attentive processes.

Voxel-Based Morphometry showed results in the superior temporal gyrus, that is a region included in IC7, but without covariates it failed to show abnormal grey matter clusters in the left hemisphere (although even with these variables the results were scattered).

In summary, as already explained by $\mathrm{Xu}$ and colleagues (2009) that compared SoBM and VBM on healthy people and schizophrenics, Source-Based Morphometry seems to be preferable to VBM because shows more noise reduction in results and because as multivariate method considers the relation among voxels (and not the single one) by detecting the clusters (in our case of grey matter) covarying between all participants (Xu et al., 2009). For this reason, SoBM seems to be more suitable for studying the abnormal cerebral anatomy in autism, since it is a disorder extended in the whole brain.

\section{Conclusions}

For the first time, our study investigated brain abnormalities in children with ASD by combining three different methods: SoBM, VBM, and SuBM. A complex but relatively coherent framework has emerged in all three approaches, stressing particularly the role of the temporal lobe that comes to light among the analyses. Although wider, a network similar to ASN emerged by SoBM in children with ASD, including temporal, frontal and parietal regions. For this reason, this network seems to be stable across ages. In literature, it has been reported that an early diagnosis could lead to better outcomes after the intervention (Dawson et al., 2012; Small \& Pelphrey, 2015). The main problem of getting an early diagnosis is that so far the most used assessment tools require abilities already structured in children, as the language. Because of that, recent research is focusing on investigating the presence of biological markers for the ASD conditions, which may overstep the limits imposed by diagnostic tests. Being a growing research interest the detection of these biomarkers for ASD (Wang et al., 2016; Small \& Pelphrey, 2015), continuing our research line in the future it would be very necessary to investigate the presence of ASN already in toddlers. If the ASN would be confirmed also in toddlers, it may be considered as an important indicator for the areas of interest. At that point, ASN in combination with Support Vector Machine (SVM) applied to brain structural MRI data of patients with ASD at any age could provide valuable inferences at single-subject level (Retico et al., 2016; Gori et al., 2015) and could be an additional tool for clinicians in the assessment and diagnosis of autistic spectrum disorder.

\section{Author contributions}

EP: Experimental design, data collection, data analyses and writing of the paper. RS: Experimental design, data collection, data analyses and writing of the paper. SV: writing of the paper. PV: writing of the paper. RJ: writing of the paper. AG: Experimental design, data analyses, writing of the paper.

This article is protected by copyright. All rights reserved. 


\section{Data Accessibility}

Structural MRI images of every participant were acquired from ABIDE. The acquisition parameters, informed consent, diagnostic criteria and specific protocols used in every site are available on the database website (http://fcon_1000.projects.nitrc.org/indi/abide/). A summary of the data used in this study is provided as a supplementary file.

\section{References}

Armstrong, E., Schleicher, A., Omran, H., Curtis, M., Zilles, K. (1995). The ontogeny of human gyrification. Cereb Cortex. 1995 Jan-Feb;5(1):56-63.

Ashburner, A., Friston, KJ. (2000). Voxel-Based Morphometry - The methods. Neuroimage 11, 805-821 (2000).

Auzias, G., Viellard, M., Takerkart, S., Villeneuve, N., Poinso, F., Da Fonséca, D., Girard, N., Deruelle, C. (2014). Atypical sulcal anatomy in young children with autism spectrum disorder. Neuroimage Clin. 2014; 4: 593-603

Bartley, A.J., Jones, D.W., Weinberger, D.R. (1997). Genetic variability of human brain size and cortical gyral patterns. Brain. 120(Pt 2):257-269

Blake, R., Turner, L.M., Smoski, M.J., Pozdol, S.L., Stone, W.L. (2003). Visual recognition of biological motion is impaired in children with autism. Psychological Science, 14, $151-157$.

Brothers, L. (1990). The social brain: a project for integrating primate behaviour and neuropsychology in a new domain. Concepts Neuroscience, 1, 27-51.

Calhoun, V.D., Adali, T. (2006). Unmixing fMRI with independent component analysis. IEEE Eng Med Biol Mag. 2006 Mar-Apr; 25(2):79-90.

Carter, E.J., Pelphrey, K.A. (2006). School-aged children exhibit domain-specific responses to biological motion. Social Neuroscience, 1, 396-411.

Cauda, F., Geda, E., Sacco, K., D’Agata, F., Duca, S., Geminiani, G., Keller, R. (2011). Grey matter abnormality in autism spectrum disorder: an activation likelihood estimation meta-analysis study. J Neurol Neurosurg Psychiatry. 2011 Dec;82(12):1304-13

Conti, E., Mitra, J., Calderoni, S., Pannek, K., Shen, K.K., Pagnozzi, A., Rose, S., Mazzotti, S., Scelfo, D., Tosetti, M., Muratori, F., Cioni, G., Guzzetta, A. (2017). Network overconnectivity differentiates autism spectrum disorder from other developmental disorders in toddlers: A diffusion MRI study. Hum Brain Mapp. 2017 Jan 17

Dahnke, R., Yotter, R.A., Gaser, C. (2012). Cortical thickness and central surface estimation. Neuroimage. 2013 Jan 15;65:336-48. doi: 10.1016/j.neuroimage.2012.09.050

This article is protected by copyright. All rights reserved. 
Di Martino, A., Yan C.G., Li, Q., Denio, E., Castellanos, F.X., Alaerts, K., Anderson, J.S., Assaf, M., Bookheimer, S.Y., Dapretto, M., Deen, B., Delmonte, S., Dinstein, I., ErtlWagner, B., Fair, D.A., Gallagher, L., Kennedy, D.P., Keown, C.L., Keysers, C., Lainhart, J.E., Lord, C., Luna, B., Menon, V., Minshew, N.J., Monk, C.S., Mueller, S., Müller, R.A., Nebel, M.B., Nigg, J.T., O’Hearn, K., Pelphrey, K.A., Peltier, S.J., Rudie, J.D., Sunaert, S., Thioux, M., Tyszka, M., Uddin, L.Q., Verhoeven, J.S., Wenderoth, N., Wiggins, J.L., Mostofsky, S.H., Milham, M.P (2014). The autism brain imaging data exchange: towards a large-scale evaluation of the intrinsic brain architecture in autism. Mol Psychiatry. 2014 Jun;19(6):659-67. doi: 10.1038/mp.2013.78.

Ecker, C., Andrews, D., Dell'Acqua, F., Daly, E., Murphy, C., Catani, M., Thiebaut de Schotten, M., Baron-Cohen, S., Lai, M.C., Lombardo, M.V., Bullmore, E.T., Suckling, J., Williams, S., Jones, D.K., Ciocchetti, A., MRC AIMS Consortium, Murphy, D.G. (2016). Relationship Between Cortical Gyrification, White Matter Connectivity, and Autism Spectrum Disorder. Cereb Cortex. 2016 Jul; 26(7): 32973309.

Eilam-Stock, T., Wu, T., Spagna, A., Egan, L.J., Fan, J. (2016). Alterations in HighFunctioning Adults with Autism Spectrum Disorder. Front Neurosci. 2016 Jun 2;10:237

Gendry-Meresse, I., Zilbovicius, M. (2005). Autism severity and temporal lobe functional abnormalities. Ann Neurol. 2005 Sep;58(3):466-9.

Gordon, R.G., Calamia, M. (2016). "Neuropsychology" in J.L. Madson (ed.), Handbook of Assessment and Diagnosis of Autism Spectrum Disorder, Autism and Child Psychopathology Series (2016).

Gori, I., Giuliano, A., Muratori, F., Saviozzi, I., Oliva, P., Tancredi, R., Cosenza, A., Tosetti, M., Calderoni, S., Retico, A. (2015). Gray Matter Alterations in Young Children with Autism Spectrum Disorders: Comparing Morphometry at the Voxel and Regional Level. J Neuroimaging. 2015 Nov-Dec;25(6):866-74. doi: 10.1111/jon.12280

Gotts, S.J., Simmons, W.K., Milbury, L.A., Wallace, G.L., Cox, R.W., Martin, A. (2012). Fractionation of social brain circuits in autism spectrum disorders. Brain 135(Pt9),2711-2725.doi:10.1093/brain/ aws160

Grecucci, A., Brambilla, P., Siugzdaite, R., Londero, D., Fabbro, F., Rumiati, R.I. (2013). Emotional resonance deficits in autistic children. J. Autism Dev. Disord. 43,616628.doi:10.1007/s 10803-012-1603-z

Grecucci, A., Rubicondo, D., Siugzdaite, R., Surian, L., Job, R. (2016). Uncovering the Social Deficits in the Autistic Brain. A Source-Based Morphometry Study. Front Neurosci. 2016 Aug 31;10:388. doi: 10.3389/fnins.2016.00388

Greenspan S. I., Wieder S. (1997). Developmental Pattern and Outcomes in Infants and Children with Disorders in Relating and Communicating: A Chart Review of 200 Cases of Children with Autistic Spectrum Diagnoses, in "The Journal of Developmental and Learning Disorders", I, pp. 87-141 
Hardan, A.Y., Jou, R.J., Keshavan, M.S., Varma, R., Minshew, N.J. (2004). Increased frontal cortical folding in autism: a preliminary MRI study. Psychiatry Res. 2004 Sep $15 ; 131(3): 263-8$.

Herringshaw, A.J., Ammons, C.J., DeRamus, T.P., Kana, R.K. (2016). Hemispheric differences in language processing in autism spectrum disorders: A meta-analysis of neuroimaging studies. Autism Res. 2016 Oct;9(10):1046-1057. doi: 10.1002/aur.1599

Johansson, G. (1973). Visual perception of biological motion and a model for its analysis. Perception \& Psychophysics, 14, 201-211

Kleinhans, N.M., Richards, T., Sterling, L., Stegbauer, K.C., Mahurin, R., Johnson, L.C., Greenson, J., Dawson, G., Aylward, E. (2008). Abnormal functional connectivity in autism spectrum disorders during face processing. Brain: A Journal of Neurology, $131,1000-1012$.

Kuhl, P.K., Coffey-Corina, S., Padden, D., Dawson, G. (2005). Links between social and linguistic processing of speech in preschool children with autism: Behavioral and electrophysiological measures. Developmental Science, 8, F1-F12.

Lee, T.W., Girolami, M., Sejnowski, T.J. (1999). Independent component analysis using an extended infomax algorithm for mixed subgaussian and supergaussian sources. Neural Comput. 1999 Feb (15; 11(2):417-41)

Libero, L.E., DeRamus, T.P., Deshpande, H.D., Kana, R.K. (2014). Surface-based morphometry of the cortical architecture of autism spectrum disorders: volume, thickness, area, and gyrification. Neuropsychologia. 2014 Sep;62:1-10. doi:10.1016/j.neuropsychologia.2014.07.001

Libero, L.E., Maximo, J.O., Deshpande, H.D., Klinger, L.G., Klinger, M.R., Kana, R.K. (2014). The role of mirroring and mentalizing networks in mediating action intensions in autism. Mol. Autism 5:50. doi:10.1186/2040- 2392-5-50

Luders, E., Thompson, P.M., Narr, K.L., Toga, A.W., Jancke, L., Gaser, C. (2006). A curvature-based approach to estimate local gyrification on the cortical surface. NeuroImage 29 (2006) 1224 - 1230

Makeig, S., Junt, T.P, Bell, A.J., Ghahremani, D., Sejnowski, T.J. (1997). Blind separation of auditory event-related brain responses into independent components. Proc Natl Acad Sci U S A. 1997 Sep 30; 94(20):10979-84

Misra, V. (2014). The Social Brain Network and Autism. Ann of Neurosci. 2014 Apr; 21(2): 69-73

Nakai, T., Muraki, S., Bagarinao, E., Miki, Y., Takehara, Y., Matsuo, K., Kato, C., Sakahara, H., Isoda, H. (2004). Application of independent component analysis to magnetic resonance imaging for enhancing the contrast of gray and white matter. Neuroimage. 2004 Jan; 21(1):251-60

This article is protected by copyright. All rights reserved. 
Nickl-Jockschat, T., Habel, U., Michel, T.M., Manning, J., Laird, A.R., Fox, P.T., Schneider, F., Eickhoff, S.B. (2012). Brain structure anomalies in autism spectrum disorder - A meta-analysis of VBM studies using anatomic likelihood estimation. Hum Brain Mapp. 2012 Jun;33(6):1470-89.

Nordahl, C.W., Dierker, D., Mostafavi, I., Schumann, C.M., Rivera, S.M., Amaral, D.G., Van Essen, D.C. (2007). Cortical folding abnormalities in autism revealed by surfacebased morphometry. J neurosci. 2007 Oct 24;27(43):11725-35.

Oberman, L.M., Hubbard, E.M., McCleery, J.P., Altschuler, E.L., Ramachandran, V.S., Pineda, J.A. (2005). EEG evidence for mirror neuron dysfunction in autism spectrum disorders. Brain Res. 24,190-198. doi: 10.1016/j.cogbrainres.2005.01.014

Osterling, J., Dawson, G. (1994). Early recognition of children with autism: A study of first birthday home videotapes. Journal of Autism and Developmental Disorders, 24, $247-$ 257.

Pappaianni, E., Siugzdaite, R., Grecucci, A. (2016). An Abnormal Cerebellar Network in Children with Autistic Spectrum Disorder: A Morphometric Study. Autism Open Access 2016, 6:3

Retico, A., Giuliano, A., Tancredi, R., Cosenza, A., Apicella, F., Narzisi, A., Biagi, L., Tosetti, M., Muratori, F., Calderoni, S. (2016). The effect of gender on the neuroanatomy of children with autism spectrum disorders: a support vector machine case-control study. Molecular autism 7:5. https://doi.org/10.1186/s13229-015-0067-3

Riddle, K., Cascio, C.J., Woodward N.D. (2016). Brain structure in autism: a voxel-based morphometry analysis of the Autism Brain Imaging Database Exchange (ABIDE). Brain Imaging Behav. 2016 Mar 3

Rossion, B., Caldara, R., Seghier, M., Schuller, A.M., Lazeyras, F., Mayer, E. (2003). A network of occipito-temporal face-sensitive areas besides the right middle fusiform gyrus is necessary for normal faceprocessing. Brain 126( $\mathrm{Pt}$ 11),23812395.doi:10.1093/brain/awg241

Small D.M., Pelphrey, K. (2015) Autism Spectrum Disorder: Sniffing Out a New Biomarker. Current Biology. Volume 25, Issue 15, 3 August 2015, Pages R674-R676

Venuti, P. (2003). L'autismo, Percorsi d'intervento. Carocci, Roma

Venuti, P. (2012). Intervento e riabilitazione nei disturbi dello spettro autistico. Carocci, Roma

Wallace, G.L., Robustelli, B., Dankner, N., Kenworthy, L., Giedd, J.N., Martin, A. (2013). Increased gyrification, but comparable surface area in adolescents with autism spectrum disorders. Brain. 2013 Jun;136(Pt 6):1956-67. Doi: 10.1093/brain/awt106

Wang H., Liang, S., Wang, M., Gao, J., Sun, C., Wang, J., Xia, W., Wu, S., Sumner, S.J., Zhang, F., Sun, C., Wu, L. (2016) Potential serum biomarkers from a metabolomics study of autism. J Psychiatry Neurosci. 2016 Jan;41(1):27-37.

This article is protected by copyright. All rights reserved. 
Wegiel, J., Flory, M., Kuchna, I., Nowicki, K., Ma, S.Y., Imaki, H., Wegiel, J., Cohen, I.L., London, E., Brown, W.T., Wisniewski, T. (2014). Brain-region-specific alterations of the trajectories of neuronal volume growth throughout the lifespan in autism. Acta Neuropathol Commun. 2:28. doi: 10.1186/2051-5960-2-28.

Xu, L., Groth, K.M., Pearlson, G., Schretlen, D.J., Calhoun, V.D. (2009). Source-Based Morphometry: the use of Independent Component Analysis to identify gray matter differences with application to schizophrenia. Human Brain Mapping 30:711-724 (2009).

Yang, D.Y., Beam, D., Pelphrey, K.A., Abdullahi, S., Jou, R.J. (2016). Cortical morphological markers in children with autism: a structural magnetic resonance imaging study of thickness, area, volume, and gyrification. Mol Autism. 2016 Jan 25;7:11. doi: 10.1186/s13229-016-0076-X

Yassa, M.A., Stark, C.E. (2009). A quantitative evaluation of cross-participant registration techniques for MRI studies of the medial temporal lobe. Neuroimage. 2009 Jan $15 ; 44(2): 319-27$

Yotter, R.A., Thompson, P.M., Gaser, C. (2011b). Algorithms to improve the Reparameterization of Spherical Mappings of Brain Surface Meshes. J Neuroimaging 2010;XX:1-14

Zilbovicius, M., Boddaert, N. (2000). Temporal lobe dysfunction in childhood autism: a PET study. Am J Psychiatry 2000; 157:1988-1993

Zilbovicius, M., Meresse, I., Boddaert, N. (2005). Neuroimaging in autism. Clinical Neuropsychiatry (2005), 2, 6, 389-396.

Zilbovicius, M., Meresse, I., Chabane, N., Brunelle, F., Samson, Y., Boddaert, N. (2006). Autism, the superior temporal sulcus and social perception. Trends Neurosci. 29, 359366. doi: 10.1016/j.tins.2006.06.004

\section{Tables' legend}

Table 1. Demographic information about participants. The presented values for Age, Full IQ, Verbal IQ, Performance IQ, ADOS scores and Total Intracranial Volume are the relative arithmetic averages; values in round brackets are the standard deviations, in square brackets the minimum-maximum range.

Table 2 Acquisition centers, MRI scanners and acquisition protocols. Informations come from ABIDE website (http://fcon_1000.projects.nitrc.org/indi/abide/)

Table 3. Independent Component 7. Talairach labels of regions of interest, Brodmann area, volume (expressed in cc) and spatial MNI coordinates with their max values are shown.

Table 4. VBM results. Contrasts, Talairach labels of ROIs, spatial coordinates and p-value on cluster-level FWE corrected are shown 
Table 5. Surface-Based Morphometry results. Cortical parameters, contrasts, hemispheres, area of interests and p-values (threshold 0.001, uncorrected) without and with age and VIQ as covariates are shown.

\section{Figures' legend}

Figure 1. SoBM returned 9 independent components. Independent component 7 resulted significant between ASD and TD children. IC7 includes: postcentral gyrus (PC); inferior parietal lobule (IPL); inferior temporal gyrus (ITG); middle temporal gyrus (MTG); middle frontal gyrus (MFG).

Figure 2. VBM results. ASD $>$ TD contrasts (threshold $p=0.001$ ) with no covariates, with Age, TIV and Verbal IQ as covariates are shown. Regions of interest: STG (superior temporal gyrus), ITG (inferior temporal gyrus), MFG (middle frontal gyrus), PreCG (precentral gyrus), PostCG (postcentral gyrus).

Figure 3. SuBM results (threshold 0.001). Cortical thickness (TD > ASD) in right temporal regions; Gyrification (TD > ASD) in superior parietal lobule; Gyrification (ASD > TD) in middle frontal gyrus (VIQ covariate). 


\section{Tables}

Table 1. Demographic information about participants. The presented values for Age, Full IQ, Verbal IQ, Performance IQ, ADOS scores and Total Intracranial Volume are the relative arithmetic averages; values in round brackets are the standard deviations, in square brackets the minimum-maximum range.

\begin{tabular}{|c|c|c|c|}
\hline & ASD & TD controls & T-test \\
\hline Participants & 39 & 42 & \\
\hline Age (years) & $\begin{array}{l}10(1) \\
{[8-12]}\end{array}$ & $\begin{array}{l}10(1) \\
{[8-12]}\end{array}$ & $\mathrm{t}(79)=-1.25, \mathrm{p}=0.21$ \\
\hline Full IQ & $\begin{array}{l}107(16) \\
{[84-148]}\end{array}$ & $\begin{array}{l}110(13) \\
{[78-142]}\end{array}$ & $\mathrm{t}(79)=-0.71, \mathrm{p}=0.48$ \\
\hline Verbal IQ & $\begin{array}{l}103(14) \\
{[75-137]}\end{array}$ & $\begin{array}{l}110(13) \\
{[87-141]}\end{array}$ & $\mathrm{t}(79)=-2.38, \mathrm{p}=0.02$ \\
\hline Performance IQ & $\begin{array}{l}111(17) \\
{[85-149]}\end{array}$ & $\begin{array}{l}107(14) \\
{[72-135]}\end{array}$ & $\mathrm{t}(79)=1.16, \mathrm{p}=0.25$ \\
\hline ADOS Communication & $\begin{array}{l}3(2) \\
{[0-7]}\end{array}$ & & \\
\hline ADOS Social & $\begin{array}{c}8(3) \\
{[3-14]}\end{array}$ & & \\
\hline $\begin{array}{c}\text { ADOS Stereotypical } \\
\text { Behav }\end{array}$ & $\begin{array}{l}3(2) \\
{[0-7]}\end{array}$ & & \\
\hline ADOS Total & $\begin{array}{l}11(4) \\
{[6-21]}\end{array}$ & & \\
\hline $\begin{array}{c}\text { Total Intracranial } \\
\left.\text { Volume (TIV, } \mathbf{m m}^{3}\right)\end{array}$ & $\begin{array}{c}1597(125) \\
{[1323-1913]}\end{array}$ & $\begin{array}{c}1593(110) \\
{[1347-1920]}\end{array}$ & $\mathrm{t}(79)=0.16, \mathrm{p}=0.87$ \\
\hline $\begin{array}{l}\text { NYU Langone Med. } \\
\text { Center }\end{array}$ & 28 & 18 & \\
\hline UCLA1 & 7 & 9 & \\
\hline
\end{tabular}




\begin{tabular}{|c|c|c|c|}
\hline UCLA2 & 4 & 5 & \\
\hline Yale Child Study Center & 0 & 8 & \\
\hline University of Pittsburgh & 0 & 2 & \\
& & & \\
\hline
\end{tabular}

Table 2 Acquisition centers, MRI scanners and acquisition protocols. Informations come from ABIDE website (http://fcon_1000.projects.nitrc.org/indi/abide/)

\begin{tabular}{|c|c|c|}
\hline Center & MRI scanner & Acquisition protocols \\
\hline $\begin{array}{l}\text { NYU Langone } \\
\text { Medical Center }\end{array}$ & $\begin{array}{l}\text { SIEMENS MAGNETOM } \\
\text { Allegra syngo MR 2004A }\end{array}$ & $\begin{array}{l}\mathrm{TR}=2530[\mathrm{~ms}], \mathrm{TE}=3.25[\mathrm{~ms}], \mathrm{TI}=1100[\mathrm{~ms}], \\
\quad \text { flip angle } 7^{\circ}, \text { Bandwidth }[200 \mathrm{~Hz} / \mathrm{px}]\end{array}$ \\
\hline UCLA Sample 1 & $\begin{array}{l}\text { SIEMENS MAGNETOM } \\
\text { TrioTim syngo MR B15 }\end{array}$ & $\begin{array}{l}\mathrm{TR}=2300[\mathrm{~ms}], \mathrm{TE}=2.84[\mathrm{~ms}], \mathrm{TI}=853[\mathrm{~ms}], \\
\text { flip angle } 9^{\circ}, \text { Bandwidth }[240 \mathrm{~Hz} / \mathrm{px}]\end{array}$ \\
\hline UCLA Sample 2 & $\begin{array}{l}\text { SIEMENS MAGNETOM } \\
\text { TrioTim syngo MR B15 }\end{array}$ & $\begin{array}{l}\mathrm{TR}=2300[\mathrm{~ms}], \mathrm{TE}=2.84[\mathrm{~ms}], \mathrm{TI}=853[\mathrm{~ms}], \\
\quad \text { flip angle } 9^{\circ}, \text { Bandwidth }[240 \mathrm{~Hz} / \mathrm{px}]\end{array}$ \\
\hline $\begin{array}{l}\text { Yale Child Study } \\
\text { Center }\end{array}$ & $\begin{array}{l}\text { SIEMENS MAGNETOM } \\
\text { TrioTim syngo MR B17 }\end{array}$ & $\begin{array}{l}\mathrm{TR}=1230[\mathrm{~ms}], \mathrm{TE}=1.73[\mathrm{~ms}], \mathrm{TI}=624[\mathrm{~ms}], \\
\quad \text { flip angle } 9^{\circ}, \text { Bandwidth }[320 \mathrm{~Hz} / \mathrm{px}]\end{array}$ \\
\hline $\begin{array}{l}\text { University of } \\
\text { Pittsburgh }\end{array}$ & $\begin{array}{l}\text { SIEMENS MAGNETOM } \\
\text { Allegra syngo MR A30 }\end{array}$ & $\begin{array}{l}\mathrm{TR}=2100[\mathrm{~ms}], \mathrm{TE}=3.93[\mathrm{~ms}], \mathrm{TI}=1000[\mathrm{~ms}], \\
\quad \text { flip angle } 7^{\circ}, \text { Bandwidth }[130 \mathrm{~Hz} / \mathrm{px}]\end{array}$ \\
\hline
\end{tabular}

This article is protected by copyright. All rights reserved. 
Table 3. Independent Component 7. Talairach labels of regions of interest, Brodmann area, volume (expressed in cc) and spatial MNI coordinates with their max values are shown.

\begin{tabular}{|c|c|c|c|c|}
\hline Area & $\begin{array}{l}\text { Brodmann } \\
\text { Area }\end{array}$ & $\begin{array}{c}\text { volume (cc) } \\
\text { L/R }\end{array}$ & $\begin{array}{c}\text { Max Value }(x, y, \\
\text { z) } L / R\end{array}$ & $\begin{array}{c}\operatorname{MNI}(\mathbf{x}, \mathbf{y}, \mathbf{z}) \\
\mathbf{L} / \mathbf{R}\end{array}$ \\
\hline Postcentral Gyrus & $1,2,3,40$ & $2.2 / 0.8$ & $\begin{array}{c}6.4(-55,-17 \\
31) / \\
4.2(55,-17,40)\end{array}$ & $\begin{array}{c}(-5.55,-1.95 \\
33) / \\
(5.55,-1.95 \\
42)\end{array}$ \\
\hline $\begin{array}{c}\text { Inferior Temporal } \\
\text { Gyrus }\end{array}$ & $20,21,37$ & $2.1 / 2.6$ & $\begin{array}{c}4.9(-55,-19,- \\
22) / \\
6.0(58,-24,-18)\end{array}$ & $\begin{array}{c}(-5.55,-18,- \\
27) / \\
(5.85,-24,- \\
2.25)\end{array}$ \\
\hline Precentral Gyrus & 4 & $0.9 / 0.5$ & $\begin{array}{c}5.5(-52,-19 \\
34) / \\
4.1(58,-16,37)\end{array}$ & $\begin{array}{c}(-5.25,-21, \\
36) / \\
(5.85,-18,39)\end{array}$ \\
\hline Temporal Sub-Gyral & 20 & $0.1 / 1.0$ & $\begin{array}{c}3.7(-33,-48 \\
40) / \\
5.3(45,-24,-21)\end{array}$ & $\begin{array}{c}(-33,-51, \\
4.05) / \\
(45,-24,-27)\end{array}$ \\
\hline $\begin{array}{c}\text { Inferior Parietal } \\
\text { Lobule }\end{array}$ & 40 & $4.5 / 0.8$ & $\begin{array}{c}5.3(-53,-37 \\
27) / \\
4.1(58,-29,36)\end{array}$ & $\begin{array}{c}(-54,-39,27) / \\
(5.85,-3.15 \\
3.75)\end{array}$ \\
\hline Supramarginal Gyrus & 40 & $1.6 / 0.3$ & $\begin{array}{c}5.2(-55,-39 \\
30) / \\
4.0(55,-41,30)\end{array}$ & $\begin{array}{c}(-5.55,-42 \\
30) / \\
(5.55,-4.35 \\
30)\end{array}$ \\
\hline $\begin{array}{c}\text { Middle Temporal } \\
\text { Gyrus }\end{array}$ & 20,21 & $1.6 / 2.9$ & $\begin{array}{l}4.3(-58,-43,-7) / \\
5.2(58,-23,-14)\end{array}$ & $\begin{array}{c}(-5.85,-4.35,- \\
1.05) / \\
(5.85,-2.25,- \\
18)\end{array}$ \\
\hline Fusiform Gyrus & 20 & $1.0 / 1.8$ & $\begin{array}{c}4.8(-50,-10,- \\
26) / \\
5.2(42,-22,-23)\end{array}$ & $\begin{array}{c}(-51,-9,- \\
3.15) / \\
(42,-21,- \\
2.85)\end{array}$ \\
\hline Insula & & $0.3 / 0.0$ & $\begin{array}{c}4.8(-53,-34 \\
21) / \\
-\end{array}$ & $\begin{array}{c}(-54,-36,21) / \\
-\end{array}$ \\
\hline
\end{tabular}




\begin{tabular}{|c|c|c|c|c|}
\hline Uncus & 20 & $0.0 / 0.2$ & $4.6(40,-14,-27)$ & $\begin{array}{c}-/ \\
(4.05,-1.35,- \\
33)\end{array}$ \\
\hline $\begin{array}{c}\text { Superior Temporal } \\
\text { Gyrus }\end{array}$ & 13,22 & $0.4 / 0.0$ & $\begin{array}{c}4.4(-58,-38 \\
21) / \\
-\end{array}$ & $\begin{array}{c}(-5.85,-4.05 \\
21) / \\
-\end{array}$ \\
\hline $\begin{array}{c}\text { Parahippocampal } \\
\text { Gyrus }\end{array}$ & 36 & $0.0 / 0.1$ & $4.2(39,-24,-21)$ & $\begin{array}{c}-/ \\
(39,-24,-27)\end{array}$ \\
\hline Extra-Nuclear & & $0.0 / 0.1$ & $3.9(19,-54,18)$ & $\begin{array}{c}-/ \\
(1.95,-57, \\
1.65)\end{array}$ \\
\hline Middle Frontal Gyrus & & $0.0 / 0.1$ & $3.6(43,16,27)$ & $\frac{-/}{(4.35,15,30)}$ \\
\hline
\end{tabular}

Table 4. VBM results. Contrasts, Talairach labels of ROIs, spatial coordinates and p-value on cluster-level FWE corrected are shown.

\begin{tabular}{|c|c|c|c|c|c|c|}
\hline Contrast & Area & $\mathbf{t}$ & $\mathbf{x}$ & $\mathbf{y}$ & $\mathbf{z}$ & $\begin{array}{c}\text { cluster- level } \\
\mathbf{p}_{(\mathrm{FWE})}\end{array}$ \\
\hline \multicolumn{7}{|c|}{ No covariate } \\
\hline $\mathbf{A S D}>\mathbf{T D}$ & R Superior Temporal Gyrus & 4.28 & 66 & -30 & 11 & 0.006 \\
\hline TD $>$ ASD & - & - & - & - & - & - \\
\hline \multicolumn{7}{|c|}{ Age as covariate } \\
\hline \multirow[t]{2}{*}{ ASD $>$ TD } & R Superior Temporal Gyrus & 4.23 & 66 & -30 & 11 & 0.003 \\
\hline & L Postcentral Gyrus & 4.18 & -48 & -29 & 51 & 0.06 (unc.) \\
\hline
\end{tabular}

This article is protected by copyright. All rights reserved. 


\begin{tabular}{|c|c|c|c|c|c|c|}
\hline TD $>$ ASD & - & - & - & - & - & - \\
\hline \multicolumn{7}{|c|}{ TIV as covariate } \\
\hline \multirow[t]{6}{*}{ ASD $>$ TD } & R Superior Temporal Gyrus & 5.08 & 68 & -30 & 9 & 0.001 \\
\hline & L Postcentral Gyrus & 4.57 & -48 & -29 & 51 & 0.003 \\
\hline & L Middle Temporal Gyrus & 3.86 & -54 & 9 & -20 & 0.005 (unc.) \\
\hline & R Middle Frontal Gyrus & 3.75 & 56 & 18 & 36 & 0.008 (unc.) \\
\hline & L Middle Frontal Gyrus & 3.90 & -53 & 32 & 33 & 0.01 (unc.) \\
\hline & R Superior Frontal Gyrus & 3.75 & 21 & 53 & 32 & 0.03 (unc.) \\
\hline TD $>$ ASD & - & - & - & - & - & - \\
\hline \multicolumn{7}{|c|}{ VIQ as covariate } \\
\hline \multirow[t]{3}{*}{ ASD $>$ TD } & R Superior Temporal Gyrus & 5.02 & 66 & -30 & 12 & 0.001 \\
\hline & R Middle Frontal Gyrus & 4.49 & 51 & 27 & 45 & 0.005 \\
\hline & L Postcentral Gyrus & 4.44 & -48 & -29 & 51 & 0.003 \\
\hline & R Precuneus & 4.21 & 14 & -60 & 35 & 0.0325 (unc) \\
\hline & L Superior Temporal Gyrus & 4.07 & -50 & 11 & -24 & 0.0216 \\
\hline & L Inferior Frontal Gyrus & 3.95 & -47 & 33 & 3 & 0.004 \\
\hline $\mathrm{TD}>\mathrm{ASD}$ & - & - & - & - & - & - \\
\hline
\end{tabular}

This article is protected by copyright. All rights reserved. 
Table 5. Surface-Based Morphometry results. Cortical parameters, contrasts, hemispheres, area of interests and p-values (threshold 0.001, uncorrected) without and with age and VIQ as covariates are shown.

\begin{tabular}{|c|c|c|c|c|c|c|c|c|}
\hline $\begin{array}{c}\text { Cortical } \\
\text { parameter }\end{array}$ & Contrast & Hemisph & Area & $\begin{array}{c}P \\
\text { value } \\
\text { (no } \\
\text { cov) }\end{array}$ & $\begin{array}{l}\text { Area } \\
\text { (age) }\end{array}$ & $\begin{array}{c}P \\
\text { value } \\
\text { (age) }\end{array}$ & $\begin{array}{c}\text { Area } \\
\text { (VIQ) }\end{array}$ & $\begin{array}{c}\text { P value } \\
\text { (VIQ) }\end{array}$ \\
\hline \multirow[t]{5}{*}{$\begin{array}{l}\text { Cortical } \\
\text { thickness }\end{array}$} & $\begin{array}{c}\mathrm{ASD}> \\
\mathrm{TD}\end{array}$ & Left & - & - & - & - & - & - \\
\hline & $\begin{array}{l}\text { TD > } \\
\text { ASD }\end{array}$ & Left & MFG & 0.389 & MFG & 0.536 & MFG & 0.201 \\
\hline & $\begin{array}{c}\mathrm{ASD}> \\
\mathrm{TD}\end{array}$ & Right & - & - & - & - & - & - \\
\hline & $\begin{array}{l}\text { TD > } \\
\text { ASD }\end{array}$ & Right & $\begin{array}{c}\text { Temp- } \\
\text { SubGyral }\end{array}$ & 0.004 & $\begin{array}{c}\text { Temp- } \\
\text { SubGyral }\end{array}$ & 0.02 & $\begin{array}{c}\text { Temp- } \\
\text { SubGyral }\end{array}$ & 0.001 \\
\hline & $\begin{array}{l}\text { TD > } \\
\text { ASD }\end{array}$ & Right & MFG & $\begin{array}{c}0.54 \\
\text { (unc.) }\end{array}$ & MFG & $\begin{array}{c}0.63 \\
\text { (unc.) }\end{array}$ & MFG & $\begin{array}{l}0.088 \\
\text { (unc.) }\end{array}$ \\
\hline \multirow[t]{4}{*}{ Gyrification } & $\begin{array}{c}\mathrm{ASD}> \\
\mathrm{TD}\end{array}$ & Left & MTG & $\begin{array}{c}0.09 \\
\text { (unc.) }\end{array}$ & MTG & $\begin{array}{c}0.11 \\
\text { (unc.) }\end{array}$ & $\begin{array}{l}\text { MTG; } \\
\text { MTG }\end{array}$ & $\begin{array}{c}0.05 \\
\text { (unc.); } \\
0.07 \\
\text { (unc.) }\end{array}$ \\
\hline & $\begin{array}{l}\mathrm{TD}> \\
\mathrm{ASD}\end{array}$ & Left & - & - & - & - & - & - \\
\hline & $\begin{array}{c}\mathrm{ASD}> \\
\mathrm{TD}\end{array}$ & Right & MFG & $\begin{array}{c}0.07 \\
\text { (unc.) }\end{array}$ & SFG & $\begin{array}{c}0.09 \\
\text { (unc.) }\end{array}$ & MFG & 0.01 \\
\hline & $\begin{array}{l}\text { TD > } \\
\text { ASD }\end{array}$ & Right & SPL & $\begin{array}{c}0.04 \\
\text { (unc.) }\end{array}$ & SPL & $\begin{array}{c}0.04 \\
\text { (unc.) }\end{array}$ & SPL & $\begin{array}{c}0.05 \\
\text { (unc.) }\end{array}$ \\
\hline Sulci depth & $\begin{array}{c}\mathrm{ASD}> \\
\mathrm{TD}\end{array}$ & Left & $\begin{array}{c}\text { Front- } \\
\text { SubGyral }\end{array}$ & $\begin{array}{c}0.16 \\
\text { (unc.) }\end{array}$ & $\begin{array}{c}\text { Front- } \\
\text { SubGyral }\end{array}$ & $\begin{array}{c}0.29 \\
\text { (unc.) }\end{array}$ & $\begin{array}{c}\text { MFG, } \\
\text { SFG }\end{array}$ & $\begin{array}{c}0.18 \\
\text { (unc.); } \\
0.29 \\
\text { (unc.) }\end{array}$ \\
\hline
\end{tabular}




\begin{tabular}{|c|c|c|c|c|c|c|c|c|}
\hline & $\begin{array}{c}\text { TD }> \\
\text { ASD }\end{array}$ & Left & - & $\begin{array}{c}0.99 \\
\text { (unc.) }\end{array}$ & - & - & - & - \\
\hline & $\begin{array}{c}\text { ASD }> \\
\text { TD }\end{array}$ & Right & MFG & $\begin{array}{c}0.13 \\
\text { (unc.) }\end{array}$ & MFG & $\begin{array}{c}0.13 \\
\text { (unc.) }\end{array}$ & $\begin{array}{c}\text { Cuneus, } \\
\text { Precuneus }\end{array}$ & $\begin{array}{c}0.07 \\
\text { (unc.); } \\
0.17 \\
\text { (unc.) }\end{array}$ \\
\hline & $\begin{array}{c}\text { TD }> \\
\text { ASD }\end{array}$ & Right & - & - & - & - & - & - \\
\hline
\end{tabular}

This article is protected by copyright. All rights reserved. 


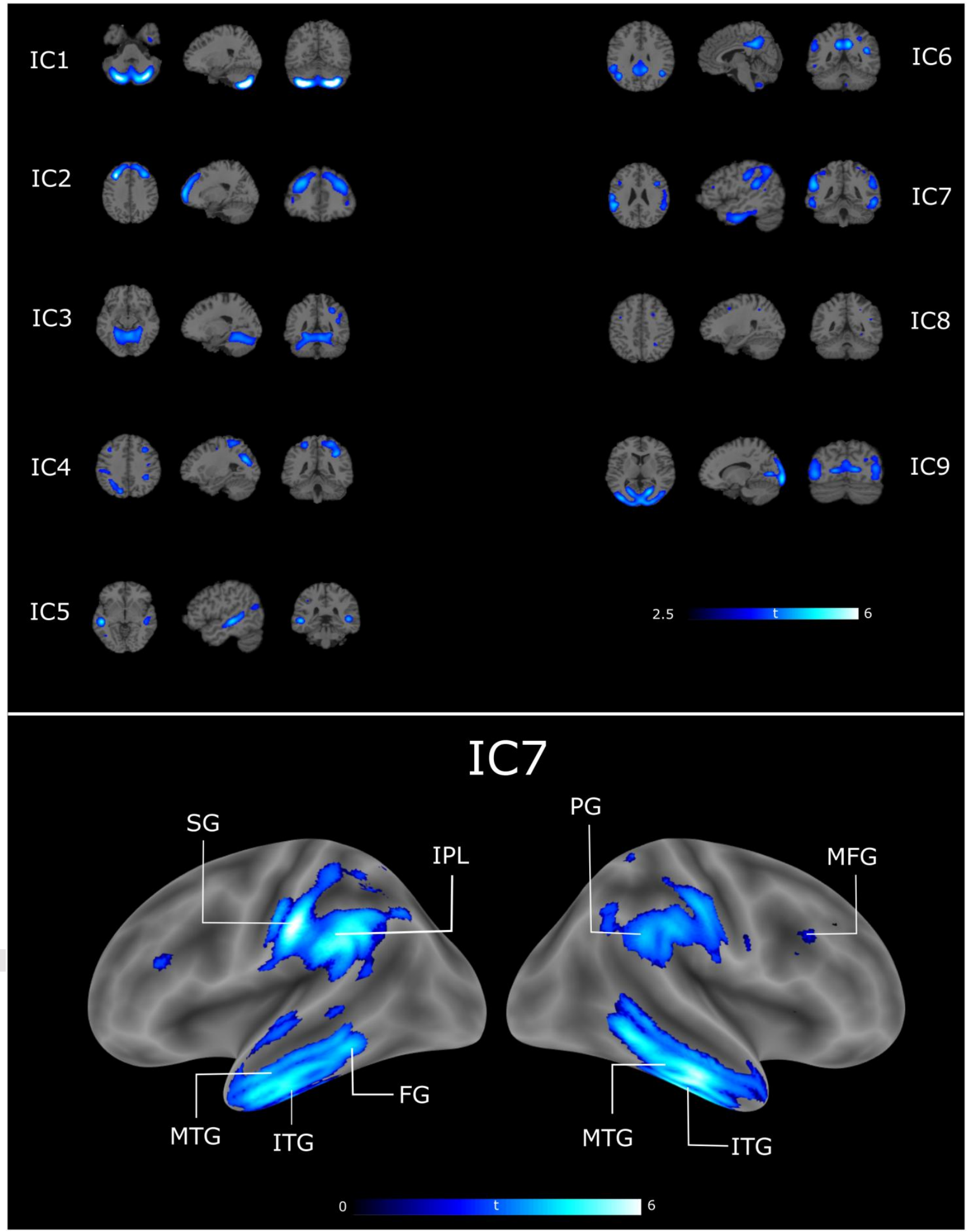

This article is protected by copyright. All rights reserved. 
No covariate
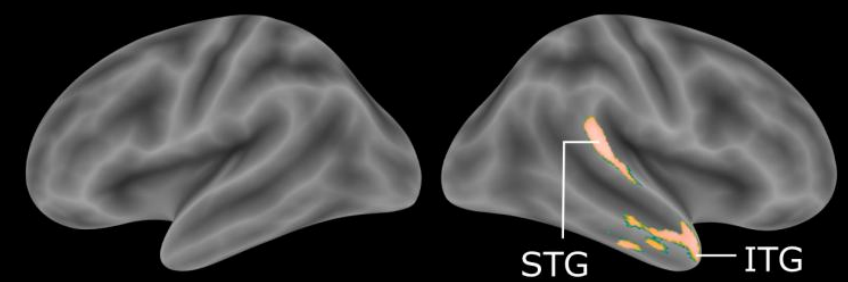

Age covariate
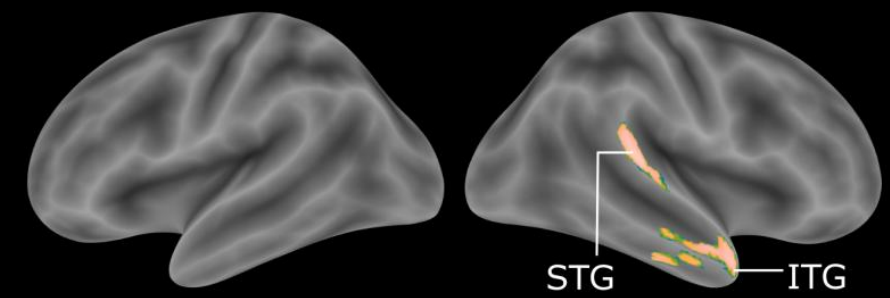

TIV covariate

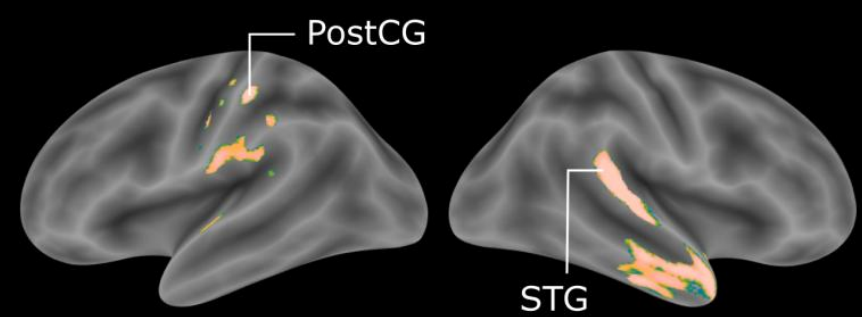

VIQ covariate

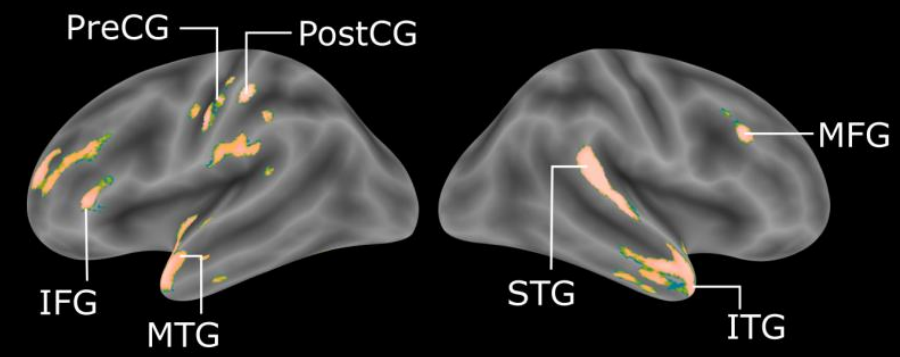




\section{Cortical thickness}
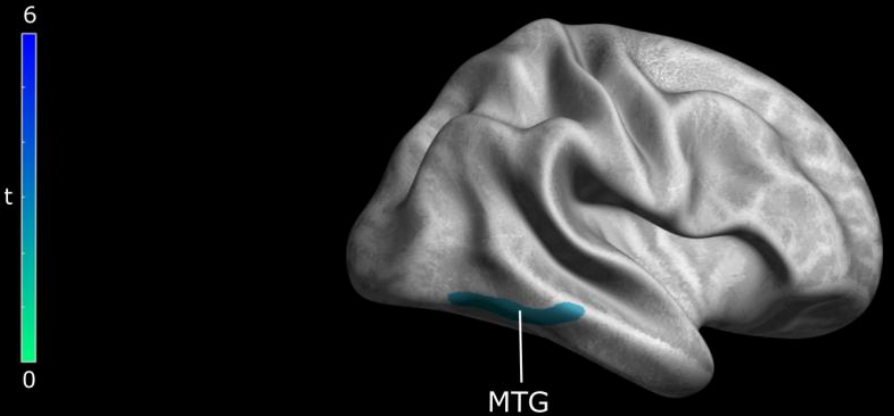

Gyrification

Right hemisphere

ASD > TD

VIQ covariate

TD $>$ ASD
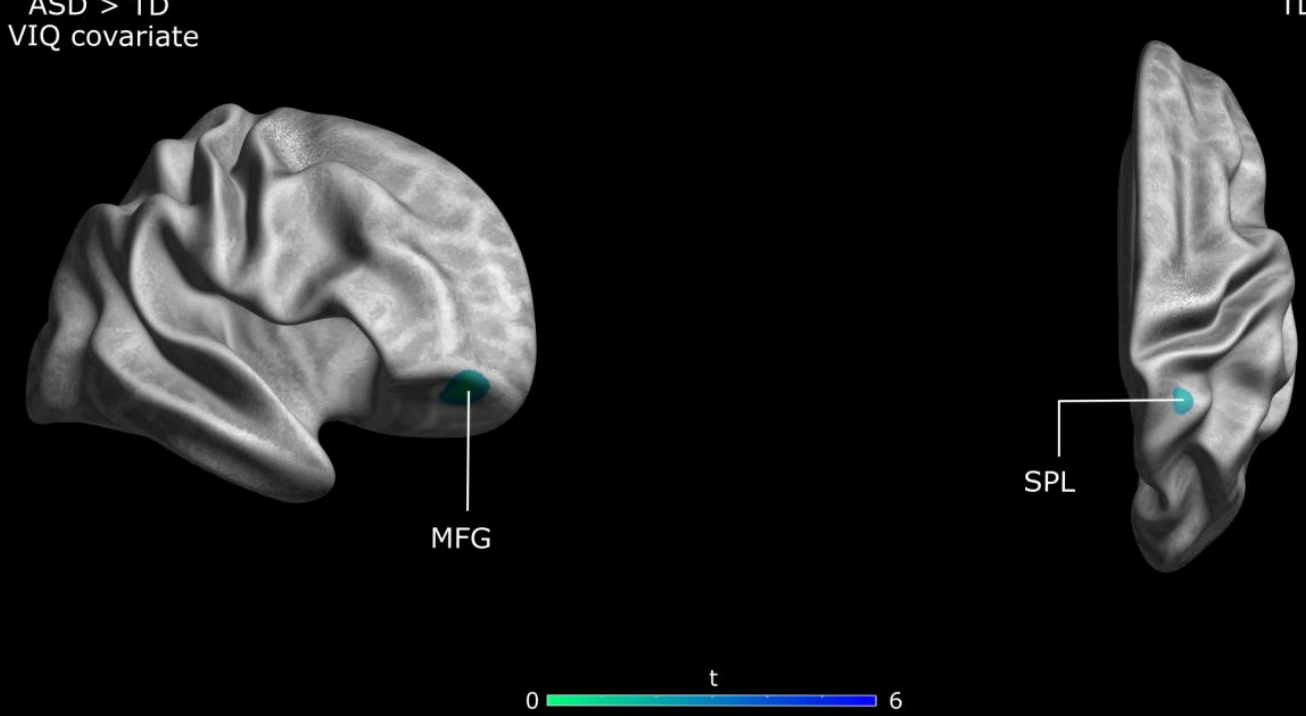

This article is protected by copyright. All rights reserved. 